\title{
Research \& Development of Automatic System for Open Caisson Method
}

\author{
Yoshitomo Tani*, Masanori Nakano**, Moriyuki Okoshi** \\ Satoshi Maeda***, and Hiizu Isa* \\ *SOCS Technology Working Group,PC Caisson Method Research Committee \\ Tobishima 2nd Bldg.,6-1,Sanbancho,Chiyoda-Ku,Tokyo,Japan \\ **Public Works Research Institute,Ministry of Construction \\ 1,Asahi,Tsukuba-City,Ibaragi-Prefecture,Japan \\ *** Research Department,Advanced Construction Technology Center \\ 2-10,2-Chome, Otowa,Bunkyo-Ku,Tokyo,Japan
}

\begin{abstract}
The open caisson method is used in a wide variety of applications such as the construction of building foundations or vertical shafts and, of the various methods available, the open caisson method has a long history of use in foundation construction. Both the structure of the caisson itself and the principles involved in the construction method are relatively simple. Also, the method is effective in terms of both cost and time. However, there are cases where, due to the ground conditions at the construction site, it is difficult to achieve the required precision in the placing of the caisson, or where problems are encountered in sinking the caisson.

The Super Open Caisson System (SOCS) was developed to improve the efficiency of the open caisson method by the introduction of automation technology in order to increase the benefits of using the method that were described above and to overcome the aforementioned problems. By doing this, it is hoped to achieve a wider range of applications for the open caisson method.

The authors, in addition to developing this system, carried out verification trials during which it was confirmed that the system was suitable for the automatic sinking of open caissons to considerable depths.

This report describes the automation technology of the two systems and the results of the verification trials of the system.

The SOCS System was developed as part of the Development of New Construction Process Technology of the Ministry of Constructions General Technology Development Projects. The system was developed from joint research carried out by the Public Works Research Institute (PWRI) of the Ministry of Construction, the Advanced Construction Technology Center (ACTEC) and 13 private companies.
\end{abstract}

\section{Introduction}

Although the principles involved in the open caisson method are relatively simple, the method enables the construction of high quality underground structures. Even at considerable depths the method can be used without the necessity of compressed air or slurry for stability. Due to the suitability of this method for construction work at considerable depths and the potential offered in labor reduction and improvement of the construction environment, the research group, led by PWRI, decided to develop a new open caisson method eliminating the various problems previously encountered with the 
method.

After consideration of the various problems the following development objectives were decided upon:

i)Automation of excavation below the caisson cutting edge

ii)Automation of caisson sinking control

iii)Improving construction of the caisson itself

These three objectives led to the development of the following three systems:

i) Automatic excavation and spoil removal system

ii) Automatic caisson sinking control system

iii) Precast caisson system

The Super Open Caisson System (SOCS) shown in Figure 1 developed as a result comprises the above three systems.

The benefits obtained by each of the three systems are outlined in Table 1. Not only can the three systems be used in combination, but, in order to meet the requirements of particular construction conditions, each of the systems can be used either independently or any two can be used in combination. A general outline is given below of the development of both the automatic excavation and spoil removal system and the automatic caisson sinking control system, as well as a report of the results of the verification trials carried out using the newly developed equipment.

\section{Overall Schematic(Guide Rail Back Hoe Type)}

\section{a) Spoil Removal Machine}
a) Automatic Excavation
Spoil Removal System
b) Press-in Device
b) Automatic Caisson
Sinking Control System

c) Precast Segment System

a) Hydraulic Grab

a) Automatic

Underwater Excavator

Figure 1 Overall Schematic of the Super Open Caisson System (SOCS)

\begin{tabular}{|c|c|c|c|c|c|c|}
\hline System & $\begin{array}{l}\text { Improvement } \\
\text { in Safety }\end{array}$ & $\begin{array}{l}\text { Improvement } \\
\text { in Quality }\end{array}$ & $\begin{array}{l}\text { Labor } \\
\text { Reduction }\end{array}$ & $\begin{array}{l}\text { Shortening of } \\
\text { Construction } \\
\text { Time }\end{array}$ & $\begin{array}{l}\text { Reduction of } \\
\text { Working Area }\end{array}$ & $\begin{array}{l}\text { Adaptabili to } \\
\text { Incleased Scale } \\
\text { and Depth }\end{array}$ \\
\hline $\begin{array}{l}\text { Automatic Excavation and } \\
\text { Spoil Removal System }\end{array}$ & & & 0 & 0 & 0 & 0 \\
\hline $\begin{array}{l}\text { Automatic Caisson Sinking } \\
\text { Control System }\end{array}$ & & 0 & $\mathrm{O}$ & & & 0 \\
\hline Precast Caisson System & 0 & 0 & 0 & 0 & 0 & 0 \\
\hline
\end{tabular}

Table 1 Advantages of the Developed Systems 


\section{Development of the Automatic Excavation and Spoil Removal System}

A comparative study was made of eight types of machine for the underwater excavation of the ground below the caisson cutting edge. The different types of machine were studied comprehensively regarding their applicability to different ground conditions, excavating performance, operability, applicability to various caisson diameters and depths, development cost and economy of excavation. As a result of this study, the guide rail back hoe and arm type road header, shown in Figure 2, were judged to be the most suitable.

For these two machines:

a) It was found that excavation of relatively soft ground with an unconfined compressive strength of up to about qu $=50 \mathrm{kgf} / \mathrm{cm}^{2}$ was best achieved with the guide rail back hoe, and for harder ground the arm type road header was found superior.

b) With regard to different caisson diameters and cost effectiveness, the arm type road header excavator was found favorable for small diameter caissons, and the guide rail back hoe was found more suitable for larger diameter caissons.

However, as the two types of excavator mutually supplement each other, it was thought appropriate to use the machine best suited to the particular excavation conditions.

The arm type road header excavator had already been developed and practically applied in construction of the substructure of the Yokohama Bay Bridge. Therefore, as a fresh development, and from the point of view of application to future large scale construction works, the guide rail back hoe was chosen for the development of the automatic underwater excavation machine.

In addition, a batch type system was adopted for spoil removal with the guide rail back hoe, to take advantage of the fact that this excavation method produces little mud. Of the two types of batch spoil removal, i.e., wire clamshell and hydraulic grab bucket methods, it was decided to adopt the latter due to its suitability for adapting automatic operation. An automatic bridge crane that runs on circular tracks was developed as the spoil removal machine. This machine was developed to prevent underwater collision between the removal bucket and the automatic excavation machine, and achieve efficient spoil removal by achieving synchronization with the excavation machine.

\subsection{Automatic Underwater Excavator}

\subsubsection{Structure}

The automatic underwater excavator runs on circular guide rails fitted to the inner wall of the caisson just above the cutting. edge. Automatic excavation of the ground inside the caisson including below the cutting edge is carried out in accordance with a pattern chosen by an operator, and the excavation spoil is gathered into the center of the excavation floor inside the caisson. The structure of the automatic underwater excavator used in the verification trials is shown in Figure 3, and the specifications can be seen in Table 2.

\subsubsection{Excavation Control System}

1) Outline

A schematic of the excavation control system is shown in Figure 4. The excavator can be controlled either automatically or manually, and to provide operational safety, an independent auxiliary manual control circuit and instrumentation are provided to enable manual operation of the automatic excavator, to control its position, grip and release, in the event of a malfunction or trouble occurring with the automatic main controller.

The automatic excavator remote control console is installed in the automatic spoil 
removal control room. The graphic monitor provides a real-time display of the current condition of the underwater excavator and shows a trace record of the excavation work. 2) Automatic Excavation Pattern

The automatic excavation patterns installed for the verification trials are shown in section and in plan in Figure 5. The required pattern is selected to suit the height of the ground within the caisson, the caisson dead weight and the geological conditions of the ground at the cutting edge.

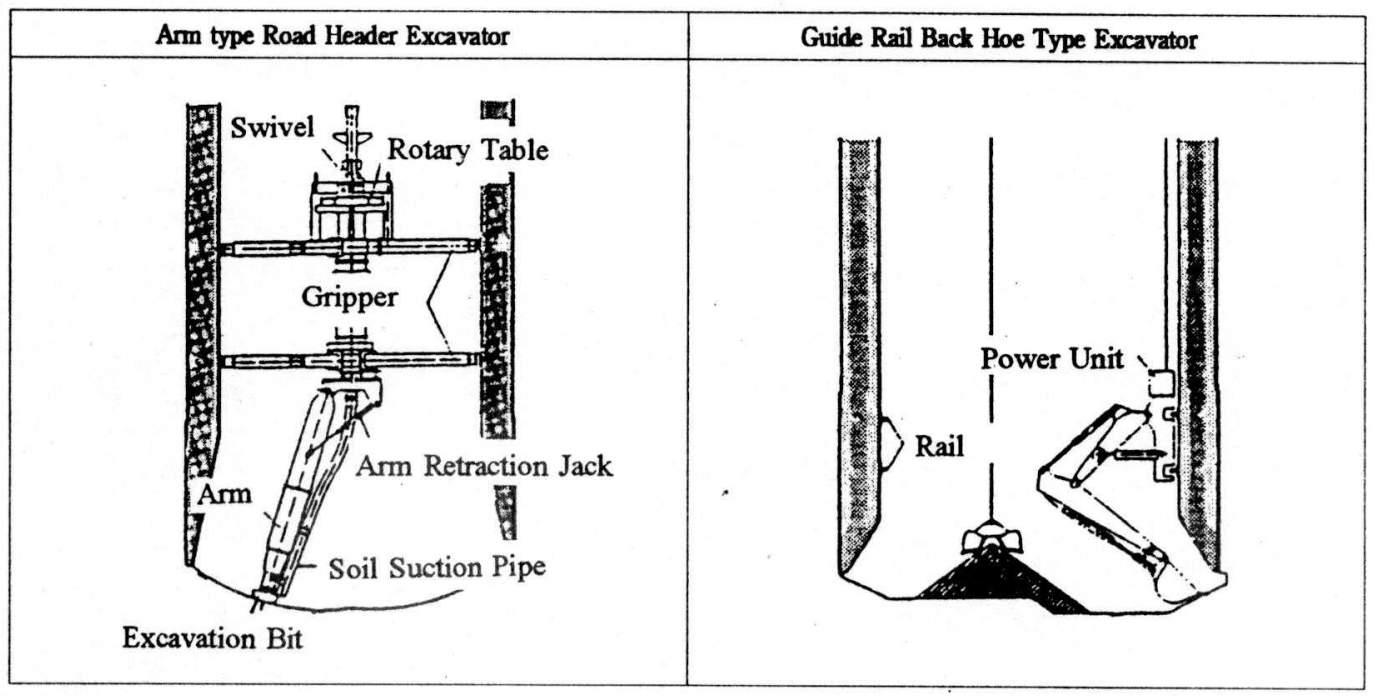

Figure 2 Automatic Underwater Excavator Proposal Schematic

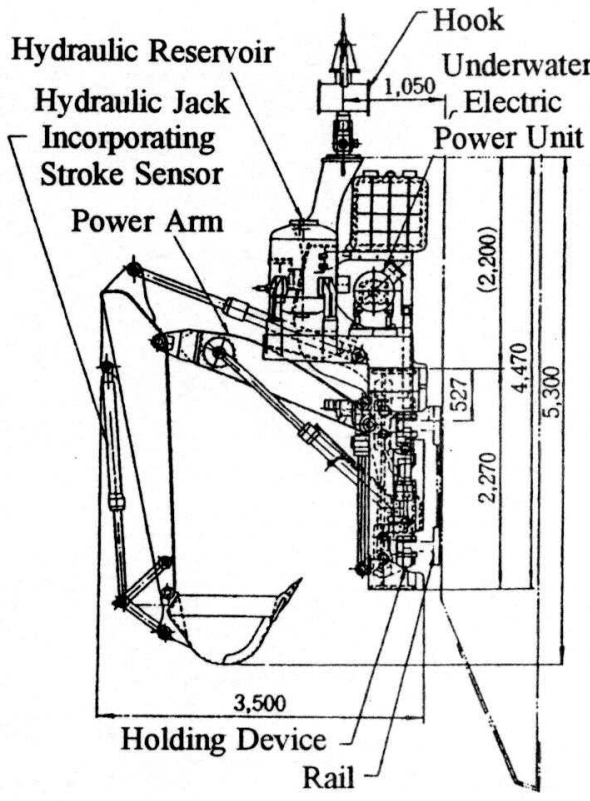

Figure 3 Underwater Excavator

\begin{tabular}{|c|c|c|}
\hline Item & Units & Specification \\
\hline \multicolumn{3}{|l|}{ - Suitable Ground } \\
\hline Normal Ground ～Hardpan & $\mathrm{kgf} / \mathrm{cm} 2$ & Less than 50 \\
\hline (Unconfined Compressive Strength) & & \\
\hline Boulder Size & $\mathbf{c m}$ & Less then 30 \\
\hline - Water Pressure Resistance Depth & m & 100 \\
\hline - Automatic Underwater Excavator & & \\
\hline Weight (in air) & kg & 14,000 \\
\hline Dimensions $(\mathrm{L} / \mathrm{W} / \mathrm{H})$ & m & $3.5 / 2.4 / 5.3$ \\
\hline \multicolumn{3}{|l|}{ - Electric Power } \\
\hline Rated Output & $\mathrm{kw} / \mathrm{rpm}$ & $55 / 1750$ \\
\hline Voltage , Frequency & $\mathbf{V} \cdot \mathbf{H z}$ & $440 \cdot 60$ \\
\hline \multicolumn{3}{|l|}{ - Grab Bucket } \\
\hline Capacity (Heaped) & $\mathrm{m} 3$ & $0.23 / 0.55$ \\
\hline Width & $\mathrm{mm}$ & $535 / 965$ \\
\hline \multicolumn{3}{|l|}{ - Hydraulics } \\
\hline Operating Pressure & $\mathrm{kgf} / \mathrm{cm} 2$ & 325 \\
\hline Travelling Device Pressure & $\mathrm{kgf} / \mathrm{cm} 2$ & 210 \\
\hline Holding Device Pressure & $\mathrm{kgf} / \mathrm{cm} 2$ & 250 \\
\hline \multicolumn{3}{|l|}{ - Excavation Range } \\
\hline Maximum Excavating Radius & m & 5.9 \\
\hline Maximum Excavating Depth & m & 4.6 \\
\hline - Travelling Speed & $\mathrm{mm} / \mathrm{sec}$ & 70 \\
\hline \multicolumn{3}{|l|}{ - Excavator Control Panel } \\
\hline Weight & kg & 400 \\
\hline Dimensions $(\mathrm{L} \times \mathrm{W} \times \mathrm{H})$ & $\mathrm{mm}$ & $1,570 \times 1,200 \times 1,170$ \\
\hline
\end{tabular}

Table 2 Automatic Underwater Excavator (Trials Machine) 


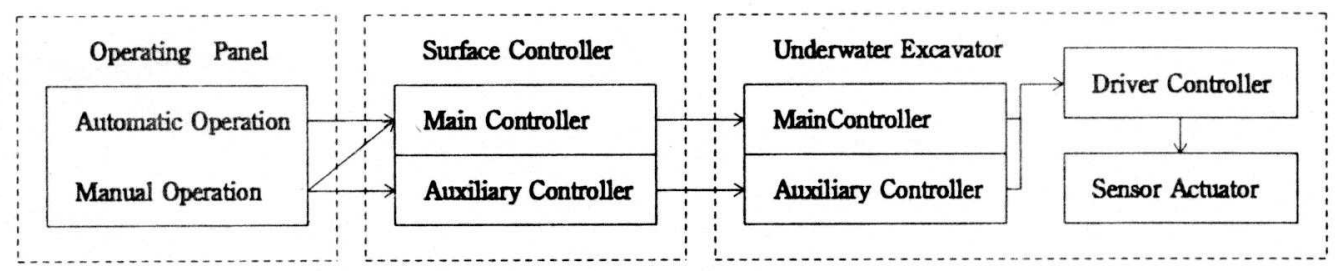

Figure 4 Excavation Control System
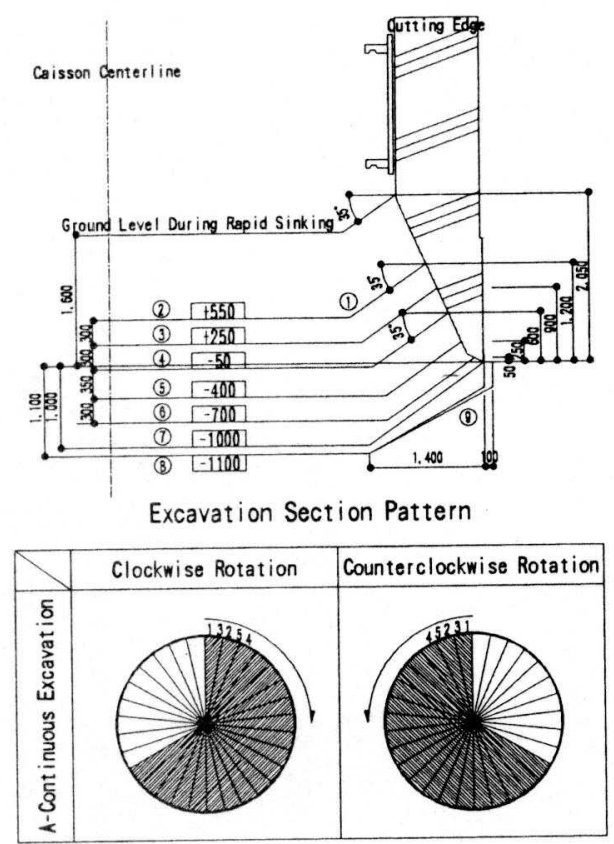

Excavation Plan Pattern(Wide Bucket)

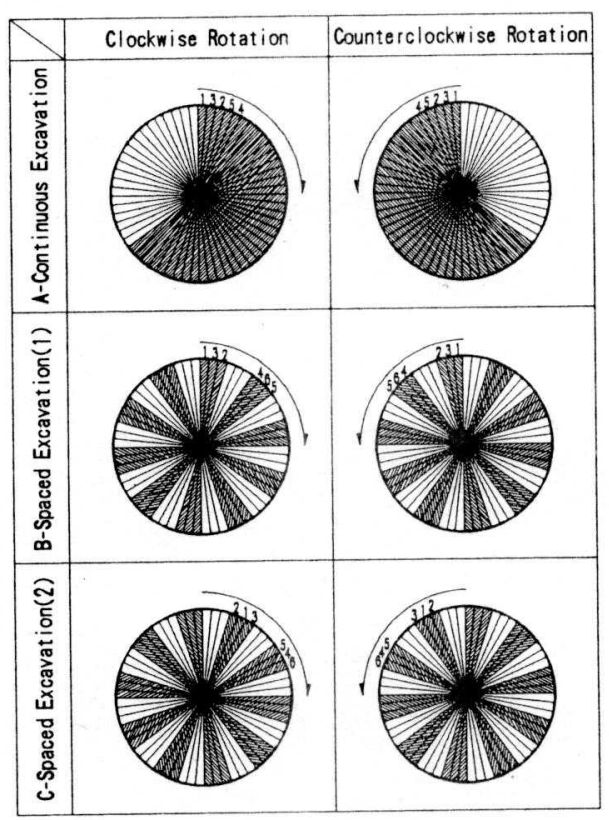

Excavation Plan Pattern(Narrow Bucket)

Figure 5 Excavation Patterns - Section and Plan

\subsection{Automatic Spoil Removal}

The bridge crane is highly versatile, providing assistance to the underwater excavation and load support in addition to its primary function of automatic spoil removal. The main functions of the crane are shown in Figure 6, they are:

(1) Coordinated automatic spoil removal (circular follower operation and coordination with excavation cycle)

(2) Following support for excavation cable (coaxial cable - power and signal) and position sensor wire

(3) Elevation and stowage of the excavator

(4) Lifting of precast members and equipment (linear travel)

(5) Operating cabin for excavation and spoil removal

\subsection{System Coordination}

It is essential that the various operations of the automatic underwater excavation system and the automatic spoil removal system, such as:

a) Excavation movement and spoil removal cycle to achieve improved efficiency without interference 
b) Lifting and lowering movement of the excavator and attachment and removal from the elevator rail

c) Emergency release

are fully coordinated. Particularly in the case of a) this coordination is necessary to prevent breaking of the automatic underwater excavator cable, and to control the relationship between the location of the gathered spoil and the position of the clamshell grab bucket to improve efficiency of spoil removal. This involves coordination of machinery travel based on information such as current position, direction of travel, destination and so on to provide a system to achieve a coordinated excavation and spoil removal cycle resulting in safe and efficient operation through mutual monitoring of the operating conditions of the various systems (e.g., depth of the hydraulic clamshell grab bucket, or whether the automatic excavator is operating or idle) to optimize efficiency and prevent collision between machinery during excavation and spoil removal.

When carrying out inspection or maintenance of the automatic underwater excavator, a special connector device is attached to the crane hook of the spoil removal machine, and by lowering along the two position sensor wires and attaching to the underwater excavator, the unit is lifted with a part of the travelling rail (elevator rail) to the top of the caisson.

In the event of the automatic underwater excavator becoming immobile while submerged, by the attachment of a removal device to the special connector device, the hydraulic pressure can be released mechanically and the excavator removed from the rail and lifted up to the surface, even if the electro-hydraulic system is inoperative.

By incorporating a radio modem link, the automatic excavation spoil removal system receives important information such as cutting edge depth, caisson crown height, caisson inclination, caisson press-in mode, and warning status from the automatic caisson sinking control system.
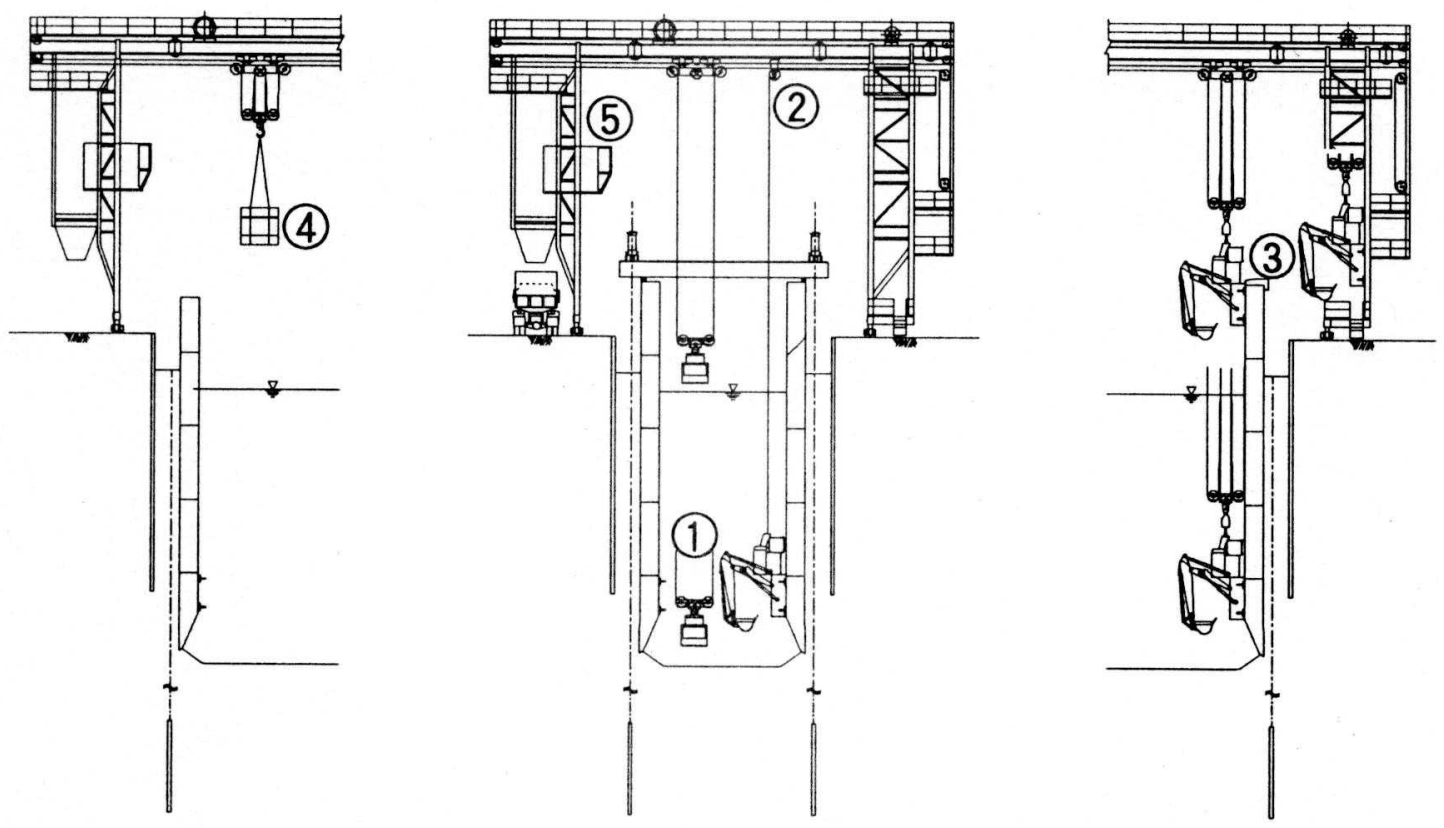

Figure 6 Automatic Spoil Removal Crane Functions 


\section{Development of the Automatic Caisson Sinking Control System}

In order to improve the efficiency of caisson sinking control, the joint research group decided to further develop press-in caisson method, a manual method of caisson sinking. This involved replacing the previous manual operation that was carried out under the judgement of an operator, with an automatic computer control system to control the press-in jacks based on data from sensors providing information on such things as caisson attitude, sinking force, and sinking resistance.

A schematic of the system is shown in Figure 7. The system comprises an automatic measuring system that receives data from the various sensors, and a press-in caisson attitude system that processes the data and automatically controls the press-in jacks.

A flow chart of the sinking procedure using the automatic caisson sinking control system, is shown in Figure 8. This system involves a reiterative process for controlling the excavation and press-in operations based on the previous caisson press-in operation. The measurements for the caisson press-in, and the control of the press-in operation are the main control functions of the automatic caisson sinking control system, which also has the supplementary function of monitoring abnormalities in the excavation process via caisson measurement.

If an excessively large inclination of the caisson is allowed to occur, correction can become impossible. Even if possible such correction can involve a great deal of time and expense and in many cases results in a horizontal displacement of the entire caisson. The system developed for the SOCS controls the caisson attitude based on data updated approximately every second to enable rapid correction of attitude deviations.

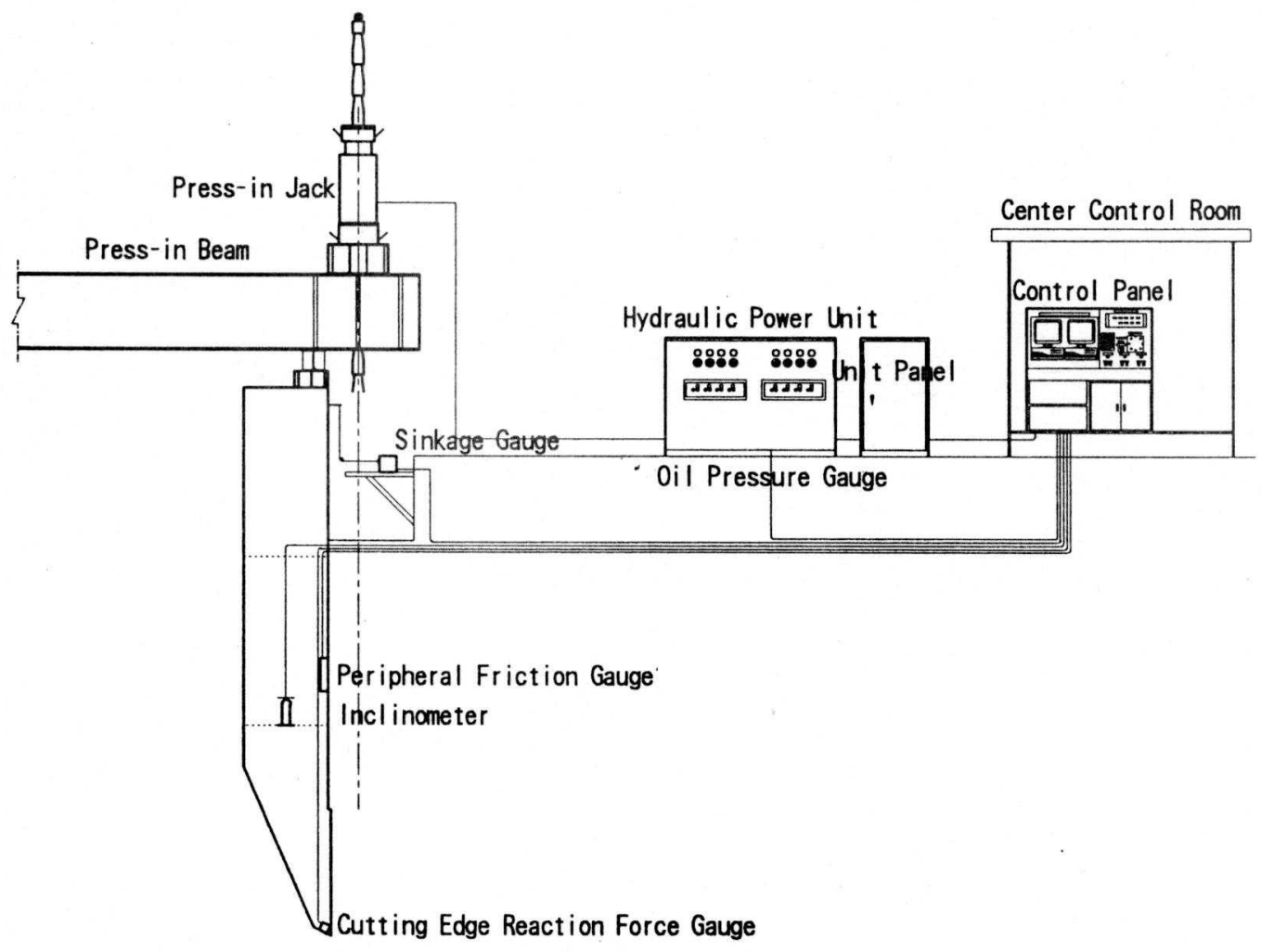

Figure 7 Automatic Caisson Sinking Control System 


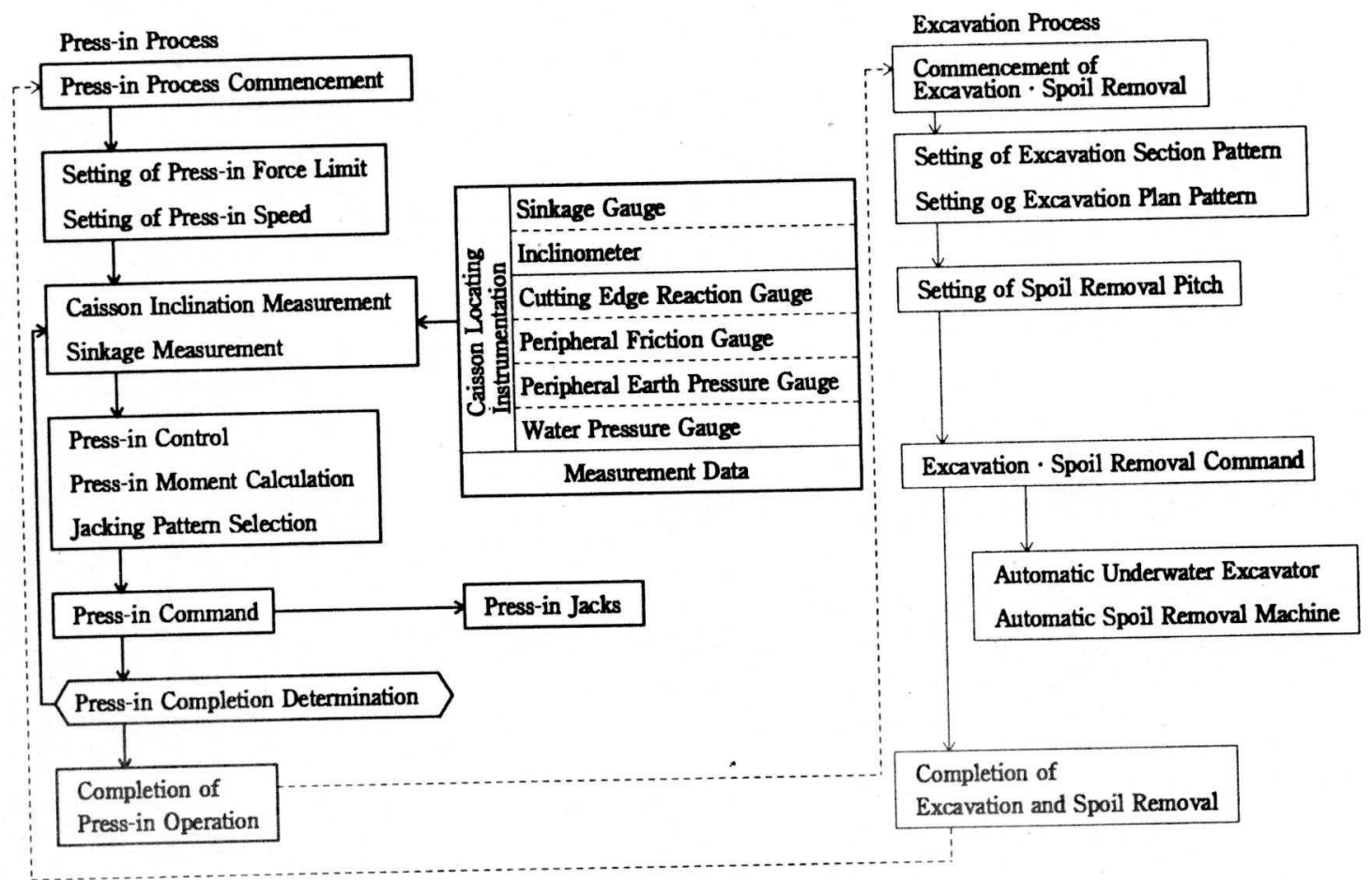

Figure 8 Flow Chart of the Sinking Procedure

\section{Results of Verification Trials}

To verify the performance of the system verification trials were carried out to sink a caisson of outer diameter $9 \mathrm{~m}$ and depth $16.5 \mathrm{~m}$ as shown in Figure 9 . From the results of a geological survey carried out at the test site, it was determined that there was no hardpan layer for which the automatic underwater excavator was developed. Therefore, a simulated hardpan layer having a strength of $\mathrm{qu}=30 \mathrm{kgf} / \mathrm{cm} 2$ was formed before commencing the trials.

\subsection{Excavation Precision}

The precision of the excavated section achieved by the automatic excavator in the sandy soil layer and in the simulated hardpan layer is shown in Figure 10. Shown in the figure is the measured excavated ground configuration after excavation by the excavator in accordance with an excavation pattern directed by the control system. In both cases the excavated section is within a few centimeters of the planned excavation line, confirming the excavation precision required for precise caisson sinking.

\subsection{Excavation for Caisson Sinking in the Simulated Hardpan Layer}

The major results achieved with the automatic underwater excavator using section and plan excavation patterns are described below.

Figure 11 shows the progress of the caisson second stage during sinking excavation. On that particular day, three excavation and press-in sinking operations were carried out using a narrow bucket. For the first operation, excavation section pattern 7 was used with spaced excavation plan pattern $\mathrm{B}$, and an press-in was performed using a force of $950 \mathrm{t}$; however, caisson sinkage of only $5.4 \mathrm{~cm}$ was achieved. The ground 
remaining from the first excavation operation was excavated using section pattern 7 with plan pattern $\mathbf{C}$ (this results in almost the entire periphery being excavated with section pattern 7), and this time a sinkage of $13.8 \mathrm{~cm}$ was achieved with a press-in force of $958 \mathrm{t}$. From these results it was concluded that even when the sandy soil was excavated almost directly below the cutting edge using pattern 7 , the cutting edge reaction was still great and the target caisson sinkage (approx. $30 \mathrm{~cm}$ ) could not be achieved. Therefore, for the third sinking operation, excavation section pattern 8 (excavation down to $30 \mathrm{~cm}$ directly below the cutting edge) was used with plan pattern $\mathrm{B}$, and after excavating the remainder with section pattern 7 and plan pattern $\mathrm{C}$, a press-in force of $660 \mathrm{t}$ was applied to achieve a resulting sinkage of $43.0 \mathrm{~cm}$ with good precision. The result of partially using excavation section 8 was to reduce the cutting edge reaction by more than $300 t$. In this way it was confirmed that by the suitable combination of excavation section and plan patterns followed by press-in the required caisson sinkage could be achieved with good precision.

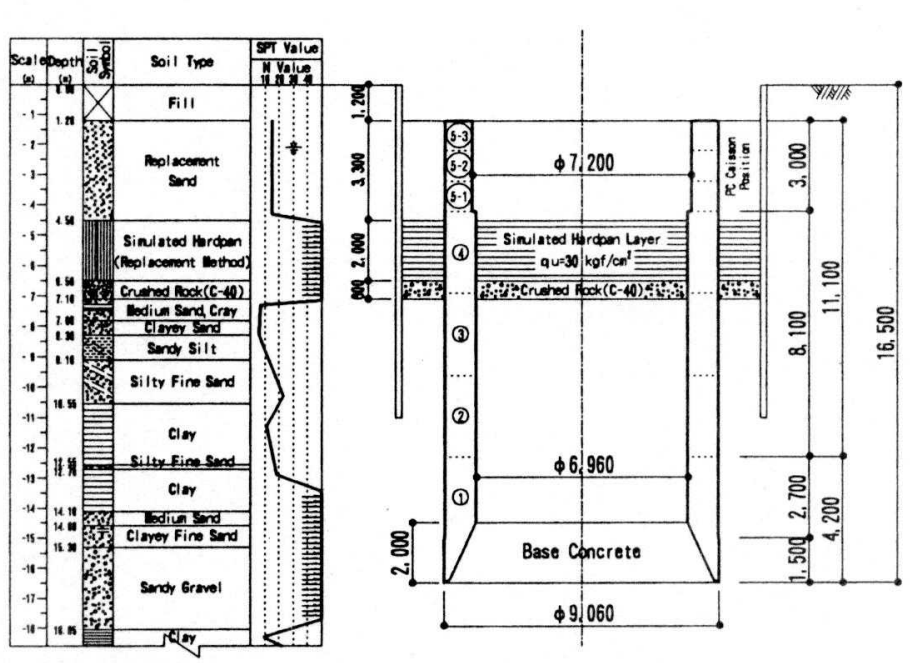

Figure 9 Cross Section of Verification Trials Caisson

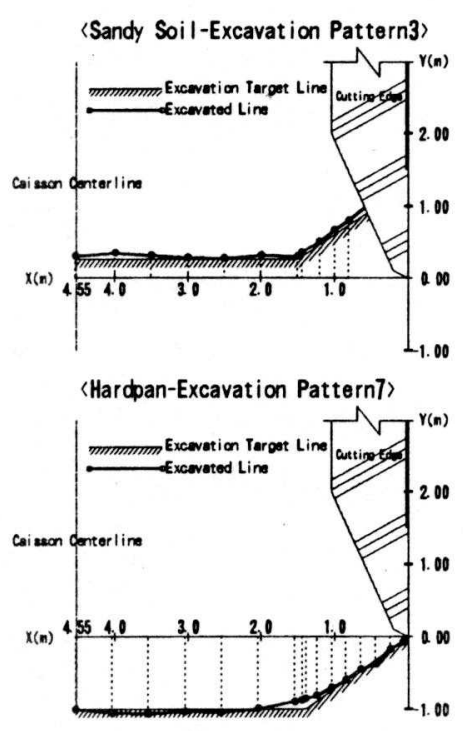

Figure 10 Automatic Excavator Excavation Precision

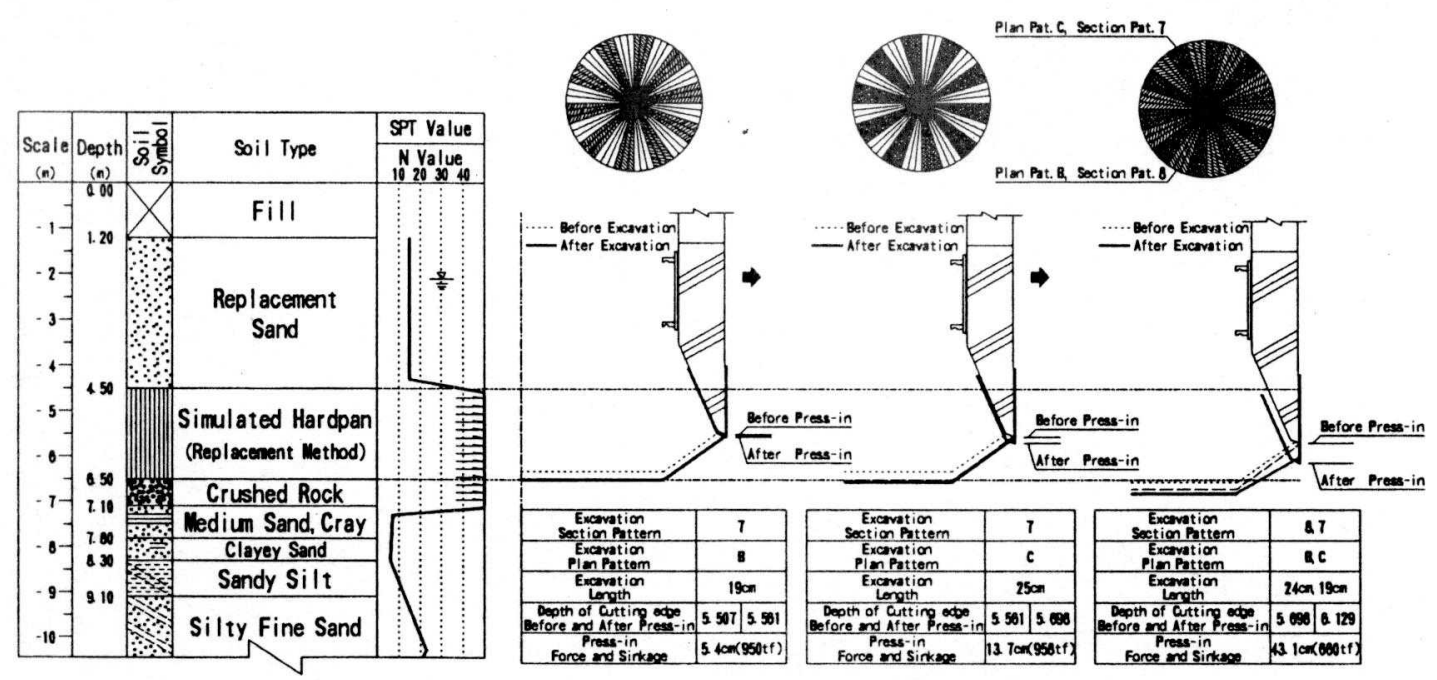

Figure 11 Progress of Caisson Second Stage During Sinking Excavation 


\section{3 Results of Application of the Automatic Caisson Sinking Control System}

The position and attitude records of the caisson during the trials are shown in figures 12 and 13. Although a certain degree of inclination of the caisson occurred temporarily during withdrawal of the foot plate and during sinking in the simulated hardpan layer, the inclination on completion was 1/5000, and horizontal movement measured at the crown was only $1 \mathrm{~mm}$. Comparison with control values of previous caisson cases show that the work was completed with an extremely high degree of precision.

Figure 14 shows the relationship between caisson sinking force (dead weight $\mathrm{Pw}+$ press-in force $\mathrm{Pj}$ ) and the sinking resistance force (cutting edge reaction force $\mathrm{Pr}+$ peripheral friction force $\mathrm{Pf}+$ uplift force $\mathrm{Pu}$ ) over the entire caisson. In addition to the improved precision of the excavation cross section control achieved by the automatic underwater excavation and spoil removal system, the actual measured values showed a relatively good match with the design values.

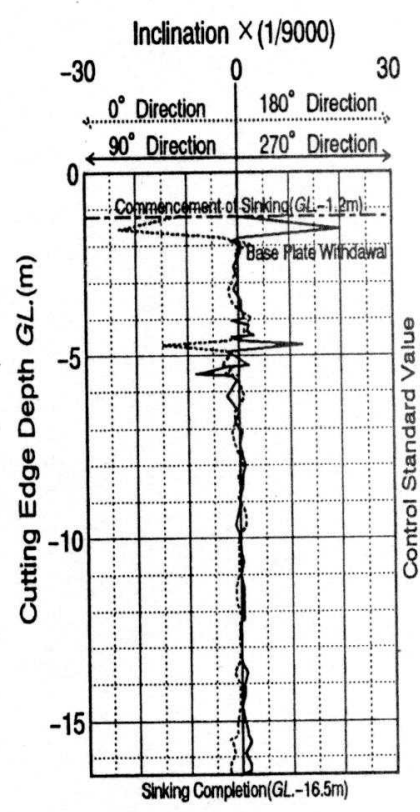

Figure 12 Inclination Control Figure 13 Graph

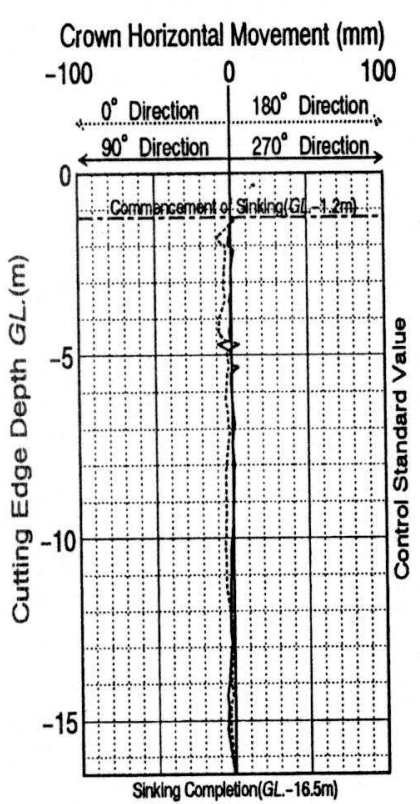

Horizontal Movement Control Graph

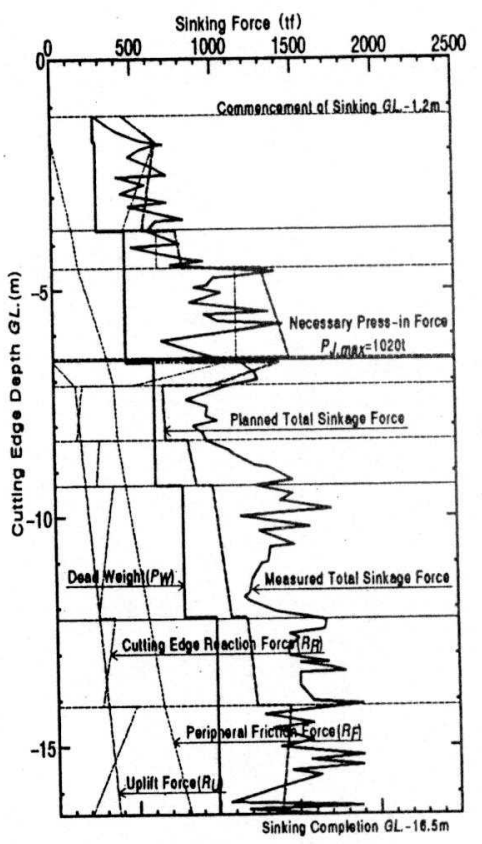

Figure 14 Relationship Between Caisson Sinking and Resistance Forces

\section{Concluding Remarks}

As a result of the verification trials, it was confirmed that the automatic open caisson method is applicable in a wide variety of ground conditions and that this technology enables the construction of a high quality underground structure at considerable depths within an improved working environment. By verifying that the underwater open caisson can be used with high precision even in relatively hard ground conditions such as hardpan that had previously caused difficulties, this new technology opens the door to the construction of large scale structures such as vertical shafts and foundations to depths exceeding $50 \mathrm{~m}$ and as deep as about $100 \mathrm{~m}$. It is now planned to make modifications and improvements to the equipment and machinery to provide a more practical method for utilization in future underground development. 